\title{
Perancangan Media Pembelajaran Pengenalan Lagu Daerah Pulau Jawa Pada Siswa Kelas 3 Sd Berbasis Web
}

\author{
Desya Meliani ${ }^{a}$, Rudy Cahyadi, $M T^{b}$, \\ ${ }^{a}$ Politeknik Negeri Media Kreatif, Jakarta \\ ${ }^{b}$ Politeknik Negeri Media Kreatif, Jakarta
}

\section{INFORMASI ARTIKEL}

Sejarah Artikel:

Diterima Redaksi: 15 November 2021

Revisi Akhir: 30 November 2021

Diterbitkan Online: 1 Desember 2021

\section{KATA KUNCI}

Media Pembelajaran, Lagu Daerah, Pulau Jawa, Website.

\section{KORESPONDENSI}

Desya Meilani

Email : desyamelianixx@gmail.com

\section{ABSTRACT}

Indonesia adalah negara yang memiliki beragam budaya. Kebudayaan yang bertahan hingga saat ini merupakan hal yang harus dilestarikan sehingga menjadi keindahan dan kekayaan yang dimiliki setiap daerah. Salah satu kebudayaan tersebut adalah Lagu Daerah. Di Pulau Jawa terdapat banyak lagu daerah yang harus dilestarikan. SBDP atau Seni Budaya dan Prakarya merupakan salah satu mata pelajaran kurikulum 2013 yang diajarkan di sekolah dasar. Pada pelajaran SBDP di SDN Cipinang Muara yang sedang mempelajari tentang lagu daerah di pulau jawa, masih ada murid yang belum paham dan mengetahui Lagu Lagu Daerah khususnya di Pulau Jawa ini karena kurangnya pengajaran dalam pengetahuan Lagu Daerah Pulau Jawa. Oleh karena itu dibangun website Media Pembelajaran Pengenalan Lagu Daerah Pulau Jawa. Website ini dibuat akan berisi materi dasar lagu daerah pulau jawa, not angka, lirik, musik, video dan kuis sebagai sarana pembelajaran dengan tampilan yang menarik, simple dan mudah dimengerti oleh anak-anak. Tujuan yang diharapkan pada pengembangan media pembelajaran ini sebagai media edukasi yang dapat membantu murid agar lebih interaktif dan mudah dalam mempelajari serta memahami Lagu Daerah di Pulau Jawa. Kesimpulan dari penelitian ini berdasarkan uji coba variabel usability didapatkan hasil persentase sebesar $88 \%$, yang artinya website ladae.my.id ini masuk ke dalam kategori sangat layak dan baik untuk digunakan.

DOI: $10.46961 /$ jommit.v5i2

\section{PENDAHULUAN}

Perkembangan pada teknologi era globalisasi saat ini menuntut manusia untuk memanfaatkan alat elektronik kecil maupun komputer dalam melakukan kegiatan sehari-hari. Salah satunya dalam pencarian informasi, saat ini pencarian informasi sudah tidak harus terpaku lagi pada buku cetak, sama halnya yang terjadi pada pemberian informasi maupun edukasi. Website merupakan salah satu media pencarian informasi. Menurut Yuhefizar (2013:2) website menggambarkan suatu metode yang berfungsi untuk menyajikan informasi di internet, berupa gambar, teks, video dan suara serta interaktif memiliki keuntungan yang menghubungkan (link) dari dokumen dengan dokumen lain seperti hypertext yang dapat diakses menggunakan browser.
Indonesia adalah negara yang memiliki beragam kebudayaan dari Sabang sampai Merauke, salah satunya adalah lagu daerah. Lagu daerah lahir dan berkembang mulai dari budaya lokal, dan merupakan lagu genetik atau bersifat turuntemurun.

Seni Budaya dan Kerajinan (SBdP) Seni Budaya dan Kerajinan maupun dikenal dengan SBdP merupakan suatu mata pelajaran pada kurikulum sekolah dasar 2013. Di sini, siswa akan belajar tentang budaya dan menciptakan seni. Di SDN Cipinang Muara terdapat mata pelajaran SBDP dengan media pembelajaran buku cetak yang dimana mempelajari budaya lokal, salah satunya adalah lagu daerah di Pulau Jawa. Berdasarkan wawancara pada salah satu guru kelas 3, beliau mengatakan siswa masih kurang memahami lagu daerah dan menyanyikan lagu daerah, entah dari nada maupun lirik lagu daerah tersebut. Sebanyak 17 siswa dari total keseluruhan 30 siswa kelas $3 \mathrm{SD}$, masih mendapatkan nilai dibawah KKM (75) saat dilakukan tes praktek harian menyanyikan lagu 
daerah. Dikarenakan masih minimnya pengetahuan siswa dan kurangnya media pembelajaran dalam mengetahui lagu-lagu daerah Pulau Jawa. Siswa hanya belajar melalui buku yang menyediakan liriknya saja lalu audio yang disediakan oleh guru serta menyanyikannya harus dibimbing oleh guru atau orangtua dirumah. Dengan demikian perlu adanya media pengenalan tentang Lagu Daerah terhadap anak-anak semenjak usia dini supaya budaya indonesia selalu lestari dan tidak luntur apalagi punah. Hal ini membuat penulis ingin menerapkan media pembelajaran interaktif.

\section{TINJAUAN PUSTAKA}

\subsection{Website}

Menurut Sibero dalam (Slamet Riyanto dan Inung Diah Kurniawati. 2018. Rancang Bangun Website Desa KresekMadiun Untuk Media Informasi Potensi Wisata Alam Dan Kuliner. Madiun: Universitas PGRI Madiun) Web yaitu sesuatu sistem yang berhubungan pada dokumen yang diperankan sebagai media buat menampilkan multimedia, gambar, teks dan lainnya atas jaringan internet. (Slamet Riyanto, 2018)

Pada penjelasan diatas bisa disimpulkan website ialah layanan jaringan berupa ruang informasi dan menampilkan sebagai bentuk gambar, teks multimedia serta lainnya pada jejaring internet.

\subsection{Pembelajaran berbasis Website}

Pembelajaran berbasis Web adalah aktivitas pembelajaran yang menggunakan media situs yang dapat diakses lewat jaringan internet. Ini disebut juga sebagai Web Based Learning, yaitu jenis penerapan pembelajaran elektronik (E-learning) atau bisa juga disebut bentuk penggunaan belajar dengan menggunakan jaringan internet buat berkomunikasi dan mengantarkan informasi pembelajaran. (Ekasari E, 2018)

\subsection{Web Development}

Web Development adalah teknologi pengembangan oleh sebuah web untuk world wide dan dunia maya. Pengembangan web yang dimaksud mempunyai ruang lingkup e-commerce melalui cakupan pengembangan bisnis, server side, client side, scripting, web server konfigurasi, serta desain web.

\subsection{Multimedia Interaktif}

Multimedia interaktif adalah gugusan beragam media (seperti gambar, bunyi, animasi, video, teks, serta grafik ) yang berkarakter interaktif (saling mensugesti atau korelasi timbal balik antara pemakai serta media) yang didesain secara teratur serta menarik dalam memberikan info atau kandungan pembelajaran sesuai menggunakan metode, materi, serta batasan tertentu. Seperti halnya hasil penelitian Sanjaya (2016) yang menyatakan bahwa kelompok belajar yang menggunakan multimedia interaktif merasa sangat puas dan peningkatan hasil belajarnya lebih besar jika dibandingkan kelompok yang tidak menggunakan multimedia interaktif.

\subsection{Pembelajaran Lagu Daerah}

\subsubsection{Lagu daerah}

Lagu daerah menurut Malatu (2014) ialah lagu yang bermula dari suatu daerah yang menjadi terkenal dan ramai dinyanyikan sama rakyat daerah tersebut kendatipun rakyat lain. Lagu daerah Indonesia tidak semata-mata alunan musik yang nikmat buat dirasakan. Tapi jua mempunyai peran ialah untuk media komunikasi, pengiring pertunjukan, permainan tradisional, serta upacara adat.

Jadi bisa menyimpulkan lagu daerah ialah lagu yang berawal dari daerah khusus yang memiliki karakteristik pada bentuk syair dan melodi lalu menjadi terkenal sebab dinyanyikan dari rakyat tersebut dan rakyat lain.

Pulau Jawa memiliki enam provinsi dan enam provinsi tersebut memiliki lagu daerah masing-masing , yakni (DKI Jakarta: KicirKicir, Jali-Jali, dan Ondel-Ondel), (Jawa Barat: Manuk Dadali, Tokecang, dan Bubuy Bulan), (Jawa Tengah: Gundul-Gundul Pacul dan Cublak-Cublak Suweng), (Jawa Timur: Rek Ayo Rek), (D.I.Yogyakarta: Suwe Ora Jamu), dan (Banten: Jereh Bu Guru dan Yu Ragem Belajar).

\subsection{Media Pembelajaran}

Media Pembelajaran (Daryanto, 2010) artinya seluruh sesuatu (baik benda, manusia, dan lingkungan) yang bisa dimanfaatkan untuk mengantarkan pesan pada pembelajaran sehingga bisa merangsang minat, perasaan, pikiran dan perhatian perasaan siswa dalam kegiatan belajar agar menggapai tujuan.

Dapat disimpulkan bahwa media pembelajaran merupakan seluruh sesuatu yang bisa menyampaikan pesan lewat bermacam saluran, mendapat perhatian, serta perasaan, dan keinginan siswa sehingga dapat mewujudkan proses belajar untuk memperbanyak informasi dan tujuan pembelajaran bisa tergapai dengan baik.

\subsection{Media Pembelajaran}

Dreamweaver menurut Sibero, (2011:384) yaitu produk web developer dan diciptakan oleh Adobe Systems Inc., sebelum itu produk Dreamweaver diciptakan oleh Macromedia Inc, lalu akhirnya sampai saat ini perkembangan diteruskan oleh Adobe Systems Inc, Dreamweaver diciptakan dan dikeluarkan menggunakan kode nama Creative Suit (CS).

\subsection{Bahasa Pemograman}

\subsubsection{HTML}

Menurut Sibero (2013) HTML adalah isyarat yang dimanfaatkan pada dokumen web sebagai isyarat untuk pergantian dokumen web"

\subsubsection{CSS (Cascading Style Sheets)}

Menurut (Sibero, 2013) mengatakan bahwa CSS mempunyai arti gaya menentukan halaman bertingkat, yang berarti setiap elemen 
yang terformat dan mempunyai anak, maka anak dari elemen itu otomatis menyertai format element induknya"

\subsubsection{PHP (Hypertext Preprocessor)}

Menurut Nugroho (2013) PHP merupakan bahasa pemrograman yang berupa scripting, sistem kerja program ini seperti interpreter bukan seperti compiler.

\subsubsection{JavaScript}

Menurut Sibero (2013) javascript merupakan scripting language yang artinya gabungan perintah yang dimanfaatkan untuk mengelola beberapa bagian sistem operasi.

$$
\text { 2.8.5 MySQL }
$$

Menurut Arief (2011) MySQL yaitu jenis database server yang populer dan ramai digunakan dalam membentuk aplikasi web saat menggunakan database sebagai sumber serta pengelolaan data.

\section{KONSEP PERANCANGAN}

Perancangan sistem website ini memanfaatkan model UML yang bermaksud untuk memperjelas dalam pengerjaan website ini, didalamnya terdapat diagram seperti Use Case Diagram, Activity

Diagram, dan Sequence Diagram.

\subsection{Use Case Diagram}

Use Case Diagram merupakan gambaran dari hubungan pengguna dengan sistem yang menunjukan interaksi antara pengguna dengan sistem. Use case dijalankan lewat cara gambaran tipe interaksi antara user program (sistem) dengan sistemnya sendiri.

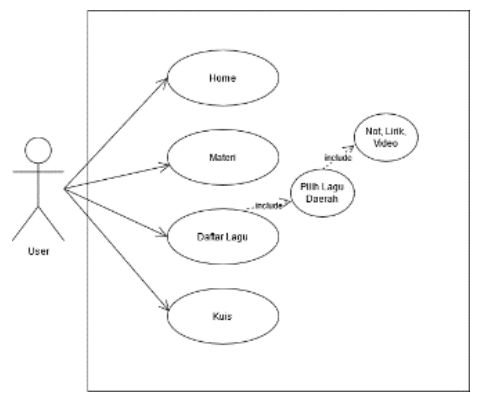

Gambar 1 Use Case Diagram

\subsection{Activity Diagram}

\subsubsection{Halaman Utama (Home)}

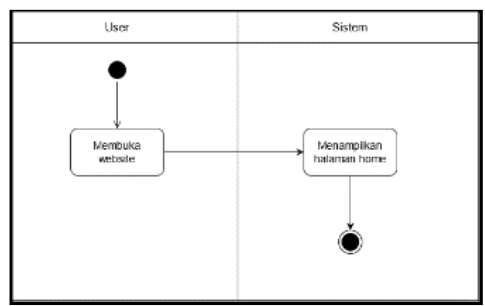

3

https://doi.org/10.46961/jommit.v5i2

\subsection{Sequence Diagram}

3.3.1 Sequence Diagram Materi

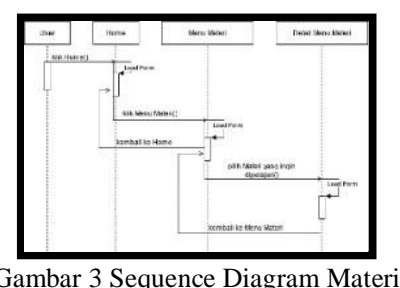

Gambar 3 Sequence Diagram Materi

\subsubsection{Sequence Diagram Daftar Lagu}

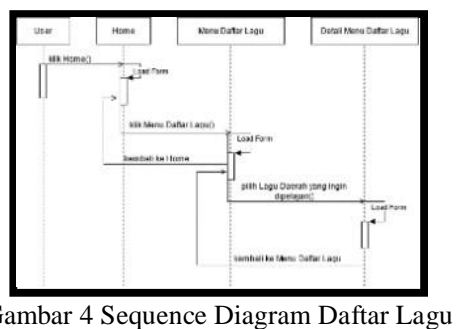

\subsubsection{Sequence Diagram Kuis}

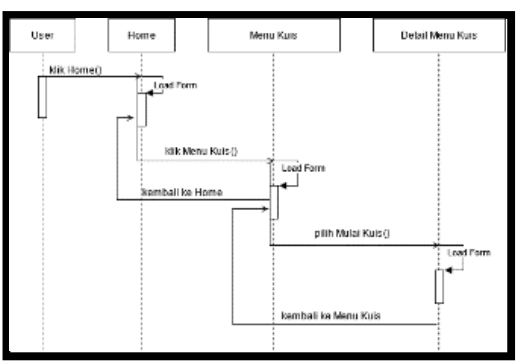

Gambar 5 Sequence Diagram Kuis

\subsection{User Interface}

Sebagai gambaran, penulis membuat struktur menu untuk website yang akan dibuat. Berikut gambaran struktur menu:

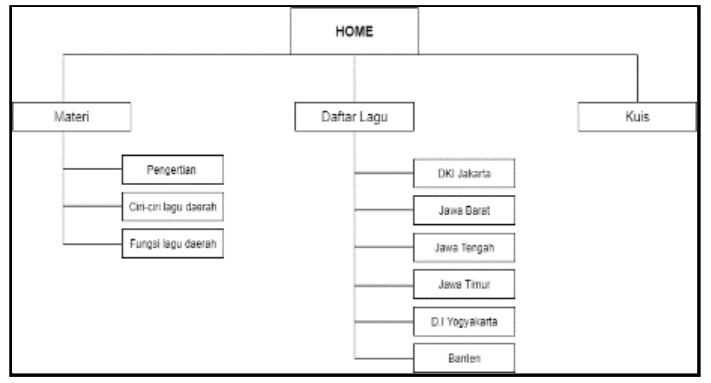

Gambar 6 User Interface 
Gambar 2 Halaman Utama 


\subsubsection{Materi}

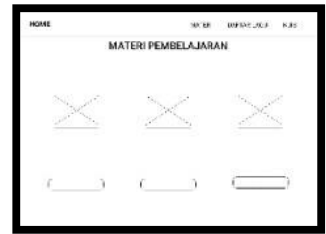

3.4.3 Daftar Lagu

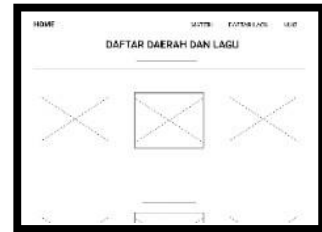

3.4 .4

Halaman Daftar Lagu per Daerah

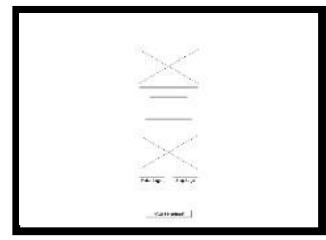

3.4.5 Kuis

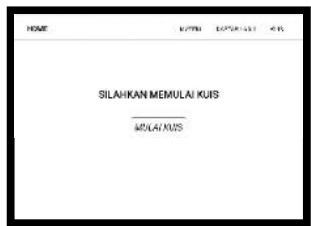

3.4 .6

Halaman Awal Mulai Kuis

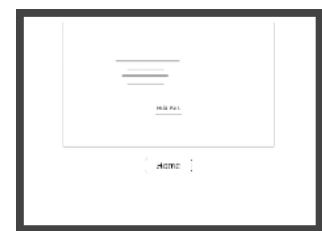

\section{HASIL DAN PEMBAHASAN}

\subsection{Hasil Produksi}

Tahap selanjutnya adalah Produksi. Pada tahapan ini penulis merancang desain tampilan user interface dan desain aset yang diperlukan dalam website, seperti latar belakang, logo, vector, dan flat design dengan menggunakan Adobe Illustrator. Setelah kebutuhan desain sudah selesai dibuat, penulis melanjutkan ke langkah berikutnya yaitu programming dengan menggunakan software Adobe Dreamweaver 2020.

\subsubsection{Kebutuhan Pemakaian Website}

1. Aset
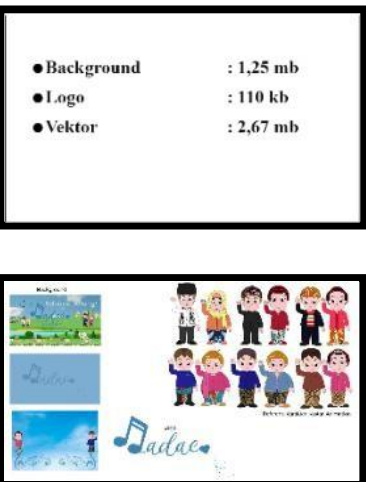

2. Audio

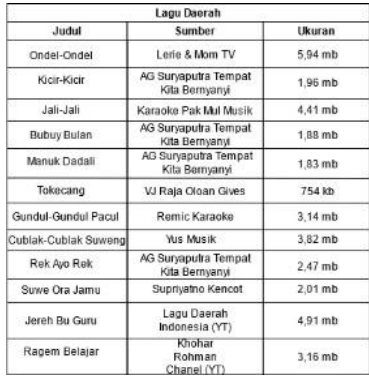

3. Video

\begin{tabular}{|c|c|c|}
\hline & & \\
\hline & & \\
\hline Conser-ondel & Dits the Seneses & $24.7 \mathrm{mb}$ \\
\hline kort-kect & Dongeng Kita & $32.8 \mathrm{mt}$ \\
\hline Jali-Jari & 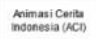 & $11.0 \mathrm{mb}$ \\
\hline Bubueveutan & $\begin{array}{c}\text { Nimasicicititi } \\
\text { mo }\end{array}$ & $127 \mathrm{mt}$ \\
\hline Totocang & Dengeno Kto & $28.7 \mathrm{mt}$ \\
\hline Manuk Dasath & Lagu Anak TV & $122 \mathrm{mt}$ \\
\hline $\begin{array}{c}\text { Cunsulu-Gunou } \\
\text { Pacoul }\end{array}$ & Solith Kats & $15.4 \mathrm{mb}$ \\
\hline Rak A A R Rek & Dto The Soneses & $50.5 \mathrm{mt}$ \\
\hline 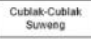 & Dna The Series & $16.2 \mathrm{mt}$ \\
\hline swe Ota Jamu & Solies nods & $33.7 \mathrm{mt}$ \\
\hline Jeren Bu Guru & $\begin{array}{l}\text { Lagu Daerah } \\
\text { honosesiat }\end{array}$ & $172 \mathrm{mt}$ \\
\hline Ragem Besapar & 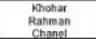 & $5,70 \mathrm{mt}$ \\
\hline
\end{tabular}

4.2.2 Tampilan AntarMuka Website

1. Tampilan Halaman Utama (Home) 


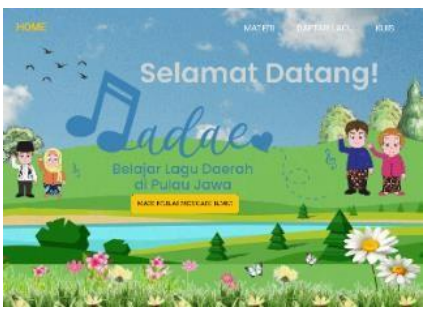

2. Tampilan Menu Materi

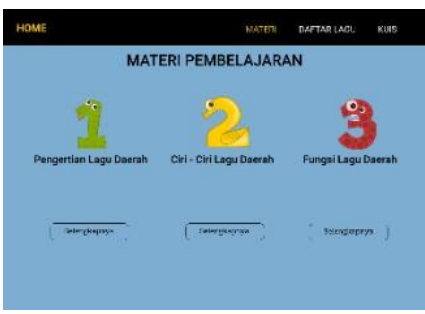

3. Tampilan Isi perMateri

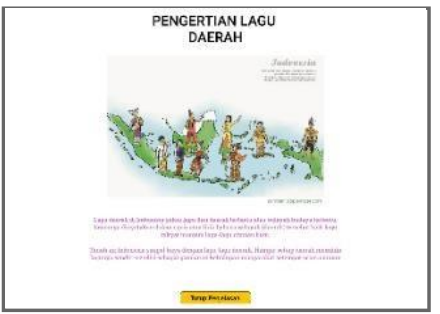

4. Tampilan Daftar Lagu

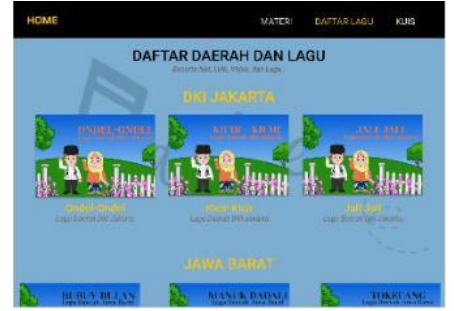

5. Tampilan Isi Daftar Lagu perDaerah

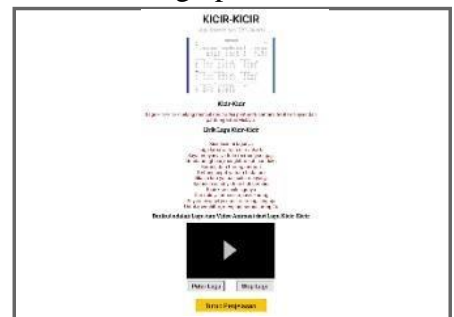

6. Tampilan Menu Kuis

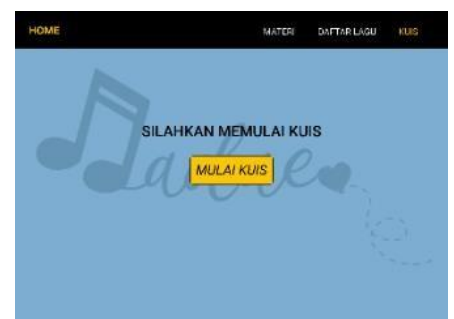

7. Tampilan Isi Kuis

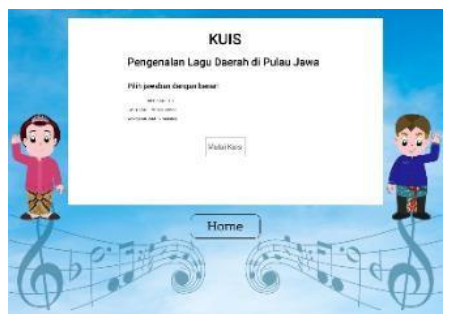

\subsection{Pengujian Sistem}

4.3.1 Uji Fungsi

\begin{tabular}{|c|c|c|c|c|}
\hline No. & $\begin{array}{l}\text { Aktivitas } \\
\text { Pengujian }\end{array}$ & $\begin{array}{l}\text { Hasil yang } \\
\text { diharapka } \\
\text { n }\end{array}$ & $\begin{array}{l}\text { Hasil } \\
\text { Pengujia } \\
\text { n }\end{array}$ & $\begin{array}{l}\text { Kesimpul } \\
\text { an }\end{array}$ \\
\hline 1. & $\begin{array}{l}\text { Klik navbar } \\
\text { "Home" }\end{array}$ & $\begin{array}{c}\text { Menampilk } \\
\text { an Halaman } \\
\text { Utama }\end{array}$ & $\begin{array}{c}\text { Tampil } \\
\text { Halaman } \\
\text { Utama }\end{array}$ & Berhasil \\
\hline 2. & $\begin{array}{l}\text { Klik navbar } \\
\text { "Materi" }\end{array}$ & $\begin{array}{c}\text { Menampilk } \\
\text { an Halaman } \\
\text { Materi }\end{array}$ & $\begin{array}{c}\text { Tampil } \\
\text { Halaman } \\
\text { Materi } \\
\text { (Pengertia } \\
\text { n, Ciri- } \\
\text { Ciri, dan } \\
\text { Fungsi) }\end{array}$ & Berhasil \\
\hline 3. & $\begin{array}{l}\text { Klik } \\
\text { "Selengkapn } \\
\text { ya" pada } \\
\text { Materi } \\
\text { Pengertian } \\
\text { Lagu Daerah }\end{array}$ & $\begin{array}{c}\text { Menampilk } \\
\text { an Halaman } \\
\text { Pengertian } \\
\text { Lagu } \\
\text { Daerah }\end{array}$ & $\begin{array}{c}\text { Tampil } \\
\text { Halaman } \\
\text { Pengertia } \\
\text { n Lagu } \\
\text { Daerah }\end{array}$ & Berhasil \\
\hline 4. & $\begin{array}{l}\text { Klik tombol } \\
\text { "Tutup } \\
\text { Penjelasan" }\end{array}$ & $\begin{array}{c}\text { Kembali ke } \\
\text { Halaman } \\
\text { Materi }\end{array}$ & $\begin{array}{c}\text { Tampil } \\
\text { Halaman } \\
\text { Materi }\end{array}$ & Berhasil \\
\hline 5. & $\begin{array}{l}\text { Klik navbar } \\
\text { "Daftar } \\
\text { Lagu" }\end{array}$ & $\begin{array}{c}\text { Menampilk } \\
\text { an Halaman } \\
\text { Daftar Lagu } \\
\text { Daerah }\end{array}$ & $\begin{array}{c}\text { Tampil } \\
\text { Halaman } \\
\text { Daftar } \\
\text { Lagu } \\
\text { Daerah }\end{array}$ & Berhasil \\
\hline 6. & $\begin{array}{l}\text { Klik } \\
\text { "Gambar" } \\
\text { pada Lagu } \\
\text { Daerah } \\
\text { Ondel-Ondel }\end{array}$ & $\begin{array}{c}\text { Menampilk } \\
\text { an Halaman } \\
\text { Lagu } \\
\text { Daerah } \\
\text { Ondel- } \\
\text { Ondel }\end{array}$ & $\begin{array}{c}\text { Tampil } \\
\text { Halaman } \\
\text { Lagu } \\
\text { Daerah } \\
\text { Ondel- } \\
\text { Ondel } \\
\text { (Not } \\
\text { Angka, } \\
\text { Tentang, } \\
\text { Lirik, } \\
\text { Musik, } \\
\text { Video) }\end{array}$ & Berhasil \\
\hline 7. & $\begin{array}{l}\text { Klik tombol } \\
\text { "Putar Lagu" }\end{array}$ & $\begin{array}{l}\text { Memulai } \\
\text { Lagu }\end{array}$ & $\begin{array}{l}\text { Mulai } \\
\text { Lagu }\end{array}$ & Berhasil \\
\hline
\end{tabular}




\begin{tabular}{|l|l|c|c|c|}
\hline 8. & $\begin{array}{l}\text { Klik tombol } \\
\text { "Stop Lagu" }\end{array}$ & $\begin{array}{c}\text { Menghentik } \\
\text { an Lagu }\end{array}$ & $\begin{array}{c}\text { Lagu } \\
\text { Berhenti }\end{array}$ & Berhasil \\
\hline 9. & $\begin{array}{l}\text { Klik tombol } \\
\text { "Tutup } \\
\text { Penjelasan" }\end{array}$ & $\begin{array}{c}\text { Kembali ke } \\
\text { Halaman } \\
\text { Daftar Lagu }\end{array}$ & $\begin{array}{c}\text { Tampil } \\
\text { Halaman } \\
\text { Daftar } \\
\text { Lagu }\end{array}$ & Berhasil \\
\hline 10 & $\begin{array}{l}\text { Klik navbar } \\
\text { "Kuis" }\end{array}$ & $\begin{array}{c}\text { Menampilk } \\
\text { an Halaman } \\
\text { Kuis }\end{array}$ & $\begin{array}{c}\text { Tampil } \\
\text { Halaman } \\
\text { Kuis }\end{array}$ & Berhasil \\
\hline 11 & $\begin{array}{l}\text { Klik tombol } \\
\text { "Mulai Kuis" }\end{array}$ & $\begin{array}{c}\text { Menampilk } \\
\text { an Halaman } \\
\text { Mulai Kuis }\end{array}$ & $\begin{array}{c}\text { Tampil } \\
\text { Halaman } \\
\text { Mulai } \\
\text { Kuis }\end{array}$ & Berhasil \\
\hline 12 & $\begin{array}{l}\text { Klik tombol } \\
\text { "Home" }\end{array}$ & $\begin{array}{c}\text { Kembali ke } \\
\text { Halaman } \\
\text { Utama }\end{array}$ & $\begin{array}{c}\text { Tampil } \\
\text { Halaman } \\
\text { Utama }\end{array}$ & Berhasil \\
\hline
\end{tabular}

Berdasarkan hasil Uji Fungsi pada tabel diatas, website bisa berjalan dengan baik serta sesuai fungsinya tanpa ditemukan kesalahan atau bug dan sesuai dengan yang diharapkan.

\subsubsection{Uji Kompatibilitas}

\begin{tabular}{|c|c|c|c|}
\hline No & Device & Pengujian & Hasil \\
\hline \multirow[t]{3}{*}{1.} & $\begin{array}{l}\text { Model: Vivo Y19 } \\
\text { Chipset: Octa-core } \\
\text { (2x2.0 GHz Cortex- } \\
\text { A75 \& 6x1.7 GHz } \\
\text { Cortex-A55) }\end{array}$ & Grafis & $\begin{array}{c}\text { Tampilan grafis } \\
\text { sudah sesuai yang } \\
\text { diharapkan tanpa } \\
\text { ada yang } \\
\text { terpotong }\end{array}$ \\
\hline & \multirow[t]{2}{*}{$\begin{array}{l}\text { OS: Android } 9.0 \text { Pie } \\
\text { Resolusi: } 1080 \mathrm{x} \\
\text { 2340 piksel, rasio } \\
\text { 19,5:9 ( 395 ppi) }\end{array}$} & Tombol & $\begin{array}{l}\text { Seluruh tombol } \\
\text { berfungsi dengan } \\
\text { baik }\end{array}$ \\
\hline & & $\begin{array}{l}\text { Audio dan } \\
\text { Video }\end{array}$ & $\begin{array}{l}\text { Seluruh audio dan } \\
\text { video berfungsi } \\
\text { dengan baik }\end{array}$ \\
\hline \multirow[t]{2}{*}{2.} & \multirow[t]{2}{*}{$\begin{array}{l}\text { Model: I-phone X } \\
\text { Chipset: Apple A11 } \\
\text { Bionic, Hexa-core } \\
2.39 \mathrm{GHz}(2 \mathrm{x} \\
\text { Monsoon + 4x } \\
\text { Mistral) }\end{array}$} & Grafis & $\begin{array}{c}\text { Tampilan grafis } \\
\text { sudah sesuai yang } \\
\text { diharapkan tanpa } \\
\text { ada yang } \\
\text { terpotong }\end{array}$ \\
\hline & & Tombol & $\begin{array}{l}\text { Seluruh tombol } \\
\text { berfungsi dengan } \\
\text { baik }\end{array}$ \\
\hline
\end{tabular}

7

https://doi.org/10.46961/jommit.v5i2

\begin{tabular}{|c|c|c|c|}
\hline & $\begin{array}{l}\text { Resolusi: } 5.8 \text { inci, } \\
1125 \text { x } 2436 \text { pixels }\end{array}$ & $\begin{array}{l}\text { Audio dan } \\
\text { Video }\end{array}$ & $\begin{array}{l}\text { Seluruh audio dan } \\
\text { video berfungsi } \\
\text { dengan baik }\end{array}$ \\
\hline \multirow[t]{3}{*}{3.} & $\begin{array}{l}\text { Model: Samsung } \\
\text { A21s } \\
\text { Chipset: Samsung } \\
\text { Exynos } 850 \text { Octa } \\
\text { core }\end{array}$ & Grafis & $\begin{array}{c}\text { Tampilan grafis } \\
\text { sudah sesuai yang } \\
\text { diharapkan tanpa } \\
\text { ada yang } \\
\text { terpotong }\end{array}$ \\
\hline & \multirow[t]{2}{*}{$\begin{array}{l}\text { OS: Android } 10 \\
\text { Resolusi: HD+ } 720 \\
\text { x } 1600 \text { pixels }\end{array}$} & Tombol & $\begin{array}{l}\text { Seluruh tombol } \\
\text { berfungsi dengan } \\
\text { baik }\end{array}$ \\
\hline & & $\begin{array}{l}\text { Audio dan } \\
\text { Video }\end{array}$ & $\begin{array}{l}\text { Seluruh audio dan } \\
\text { video berfungsi } \\
\text { dengan baik }\end{array}$ \\
\hline \multirow[t]{3}{*}{4.} & \multirow{3}{*}{$\begin{array}{l}\text { Model: Samsung } \\
\text { J6+ } 2018 \\
\text { Chipset: Qualcomm } \\
\text { MSM8917 } \\
\text { Snapdragon } 425 \text { (28 } \\
\text { nm) } \\
\text { OS: Android } 10 \\
\text { Resolusi: } 720 \text { x } \\
\text { 1480 pixels, } 18.5: 9 \\
\text { ratio ( 274 ppi } \\
\text { density) }\end{array}$} & Grafis & $\begin{array}{c}\text { Tampilan grafis } \\
\text { sudah sesuai yang } \\
\text { diharapkan tanpa } \\
\text { ada yang } \\
\text { terpotong }\end{array}$ \\
\hline & & Tombol & $\begin{array}{l}\text { Seluruh tombol } \\
\text { berfungsi dengan } \\
\text { baik }\end{array}$ \\
\hline & & $\begin{array}{l}\text { Audio dan } \\
\text { Video }\end{array}$ & $\begin{array}{l}\text { Seluruh audio dan } \\
\text { video berfungsi } \\
\text { dengan baik }\end{array}$ \\
\hline
\end{tabular}

Berdasarkan hasil Uji Kompatibilitas pada tabel diatas, website dapat digunakan dalam empat device yang berbeda spesifikasinya dengan grafis yang menyesuaikan tampilan ukuran dan resolusi smartphone, lalu semua tombol, audio, dan video dapat berfungsi dengan baik pula.

\subsubsection{Uji Usability}

1. Tabel Pertanyaan

\begin{tabular}{|c|l|c|c|c|c|c|}
\hline No & Pertanyaan & 1 & 2 & 3 & 4 & 5 \\
\hline \multicolumn{5}{|c|}{ Learnability } \\
\hline 1 & Tampilan website menarik? & & & & & \\
\hline 2 & $\begin{array}{l}\text { Penggunaan website mudah } \\
\text { diakses dan mudah digunakan? }\end{array}$ & & & & & \\
\hline 3. & $\begin{array}{l}\text { Materi pembelajaran yang } \\
\text { disediakan sudah jelas dan dapat } \\
\text { dipahami? }\end{array}$ & & & & & \\
\hline
\end{tabular}




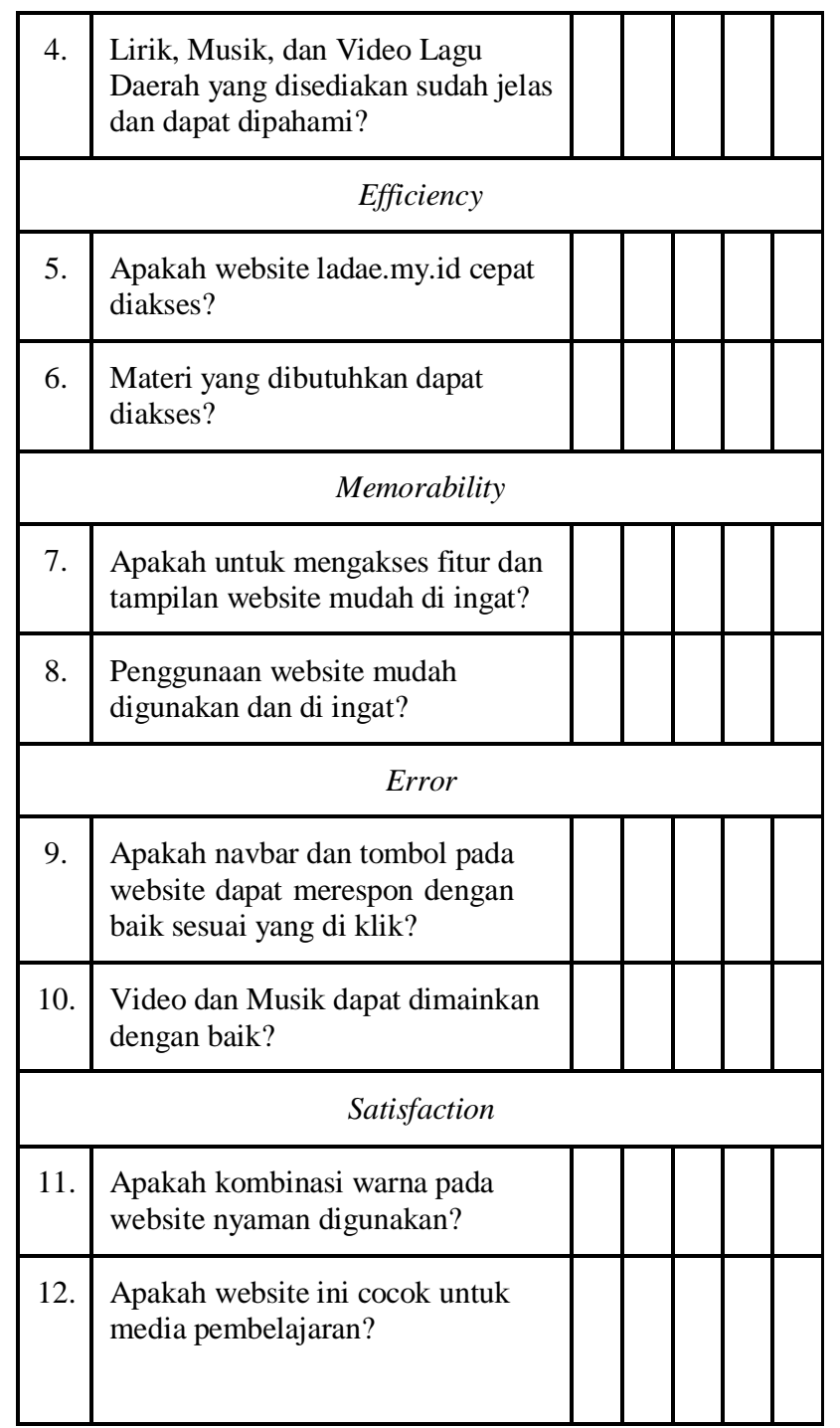

2. Tabel Hasil Kuisioner

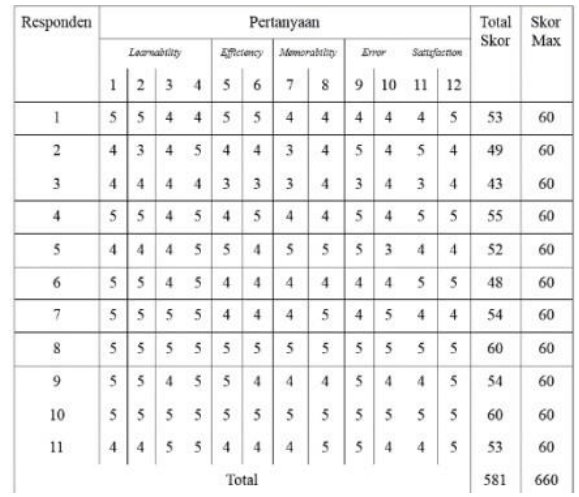

Dari data diatas, dapat diperoleh kelayakan dari penggunaan media pembelajaran berbasis website, sebanyak 11 orang responden yang telah menjawab pertanyaan dari kuesioner yang penulis berikan, nilai yang didominasi dari tabel diatas adalah 4 dan 5 dan untuk nilai terendahnya adalah 3. Maka dari itu, dapat dihitung persentase kelayakan dari website ini, seperti berikut:

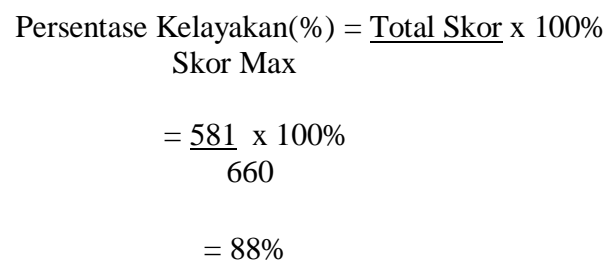

Hasil dari hitung persentase kelayakan media pembelajaran berbasis website yaitu $88 \%$, yang menyatakan bahwa website ladae.my.id ini masuk ke dalam kategori sangat layak dan baik untuk digunakan.

\section{KESIMPULAN DAN SARAN}

\subsection{Kesimpulan}

Kesimpulan karya tugas akhir tentang Perancangan Media Pembelajaran Pengenalan Lagu Daerah Pulau Jawa Pada Siswa Kelas 3 Sd Berbasis Web ini adalah tercetusnya pembuatan website sebagai media pembelajaran lagu daerah karena siswa masih kurang memahami lagu daerah dan menyanyikan lagu daerah, entah dari nada maupun lirik lagu daerah tersebut. Proses pembuatan website ini meliputi serangkaian proses yaitu, mengidentifikasi masalah, pengumpulan data, merancang konsep, membuat sketsa, membuat desain user interface serta aset, programming, mem-build website, dan uji coba website.

Dari hasil pengujian penulis melakukan tiga tahap pengujian yaitu, uji fungsi, uji kompatibilitas, dan uji usability. Dari tiga pengujian tersebut diperoleh kesimpulan sebagai berikut:

1. Dalam Uji Fungsi penulis memperoleh hasil bahwa website ladae.my.id berhasil berjalan dengan baik dan sesuai sebagaimana fungsinya serta tanpa ditemukan kesalahan maupun bug dan sesuai dengan apa yang diharapkan.

2. Dalam Uji Kompatibilitas penulis memperoleh hasil bahwa website ladae.my.id dapat digunakan dalam empat device yang berbeda spesifikasinya dengan grafis yang menyesuaikan tampilan ukuran dan resolusi smartphone, lalu semua tombol, audio, dan video berhasil berfungsi dengan baik pula dan sesuai dengan apa yang diharapkan.

3. Dalam Uji Usability hasil dari hitung persentase kelayakan media pembelajaran berbasis website yaitu $88 \%$, yang menyatakan bahwa website ladae.my.id ini masuk ke dalam kategori baik dan layak untuk digunakan.

\subsection{Saran}

Mengenai hal ini tentunya penulis sadar akan hal bahwa website ini masih penuh dengan kekurangan. Beberapa hal yang dapat di kembangkan dan ditambahkan dalam website ini berupa:

1. Materi Pembelajaran lagu daerah dapat ditambahkan lagi agar siswa menerima materi lebih banyak;

2. Lagu Daerah di pulau jawa dapat ditambahkan lagi; 
3. Fitur lain agar dapat ditambahkan supaya website ini menjadi lebih menarik dan interaktif lagi.

\section{DAFTAR PUSTAKA}

[1] Abdul Kadir dan Terra Ch. Triwahyuni. 2013. Pengantar Teknologi Informasi Edisi Revisi. Yogyakarta: Andi

[2] Alatas, H. (2013). Responsive Web Design dengan PHP \& Bootstrap. Yogyakarta: Lokomedia.

[3] Alexander F. K. Sibero, 2011, Kitab Suci Web Programming, MediaKom, Yogyakarta.

[4] Anhar. 2010. "PHP \& MySQL Secara Otodidak". Jakarta: Agromedia Pustaka.

[5] Arief, M.Rudyanto., 2011, Pemrograman Web Dinamis Menggunakan PHP dan MYSQL, Andi, Yogyakarta.

[6] Arikunto, Suharsimi, \& Safruddin A.J, Cepi.2009. Evaluasi Program Pendidikan. Jakarta: Bumi Aksara.

[7] Ekasari E, Sabrianti S, dan Setiawan U. 2018. Modul Media Pembelajaran Berbasis Web. Kendari: Institut Agama Islam Negeri(IAIN)

[8] Muhammad Munsarif Jamaludin, dan Janner Smarmata. 2020. Media Pembelajaran. Medan: Yayasan Kita Menulis.

[9] Kesuma, Chandra \& Juniati, Melda Dwi. 2020. Sistem Informasi Administrasi Kependudukan Desa (SIAKSA) Berbasis Web pada Desa Alangamba Kabupaten Cilacap. Journal SpeedSentra Penelitian Engineering dan Edukasi. Vol.12, No.1.

[10] Kreswanto, Fendi Nur. 2018. I-SCEM (Indonesia Song Culture Education Mobile) Sebagai Media Pembelajaran Pengenalan Lagu Daerah Indonesia. Pedagogia : Jurnal $\begin{array}{lllll}\text { Pendidikan. } & \text { Vol. } & 7, & \text { No.1. }\end{array}$ https://doi.org/10.21070/pedagogia.v7i1.1404

[11] Lim, Virya Darma \& Wibowo, Tony. 2019. Perancangan Media Sosialisasi Lagu Daerah Indonesia Menggunakan Pendekatan Electronic Dance Music. Journal of Information System and Technology. Vol.01 No.02. pp. 16-30. http://dx.doi.org/10.37253/joint.v1i2.4307

[12] Rusman. 2012. Model Model Pembelajaran: Mengembangkan Profesionalisme Guru. Jakarta: Rajawali Pers.

[13] Sari, Heni Vidia \& Suswanto, Harry. 2017. Pengembangan Media Pembelajaran Berbasis Web Untuk Mengukur Hasil Belajar Siswa Pada Mata Pelajaran Komputer Jaringan Dasar Program Keahlian Teknik Komputer Dan Jaringan. Jurnal $\begin{array}{llll}\text { Pendidikan. } & \text { Vol. } & 2 & \text { No.7. }\end{array}$ http://dx.doi.org/10.17977/jptpp.v2i7.9734

[14] Setiowati, Shintya Putri. 2020. Pembentukan Karakter Anak Pada Lagu Tokecang Jawa Barat. Jurnal Ilmu Budaya. Vol.8, 9

https://doi.org/10.46961/jommit.v5i2
[15] Slamet, Riyanto \& Kurniawati, Inung Diah. 2018. Rancang Bangun Website Desa Kresek-Madiun Untuk Media Informasi Potensi Wisata Alam Dan Kuliner. Jurnal Sistem Informasi Ilmu Komputer Prima.Vol. 1 No. 2. 44-46.

http://jurnal.unprimdn.ac.id/index.php?journal=JUSIKOM

[16] Sibero, Alexander F.K . 2013. Web Programming Power Pack. Yogyakarta : Mediakom.

[17] Tonny, Limbang dan Janner Simarmata. 2020. Media dan Multimedia Pembelajaran: Teori \& Praktik. Medan: Yayasan Kita Menulis

[18] http://www.waskhas.com/2020/02/pengertian-use-casediagram-dan.html diakses pada 7 juli 2021 jam 23.44

[19] https://www.ansoriweb.com/2020/03/pengertian-use-casediagram.html diakses pada 7 juli 2021 jam 23.54

[20] http://craiovaonline.com/teknologi/pengertian-websitedevelopment-dan-website-developer/ diakses pada 20 Agustus 2021 jam 14.30

\section{BIODATA PENULIS}

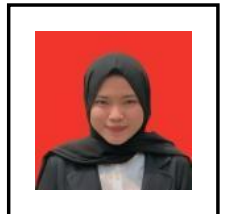

\begin{abstract}
Nama Mahasiswa
Desya Meliani merupakan mahasiswa tingkat akhir Multimedia Politeknik Negeri Media Kreatif Jakarta angkatan 2018. Lahir di Jakarta, 21 Desember 1999 dan bertempat tinggal di Bekasi. Memiliki hobi membaca wattpad dan berenang.
\end{abstract}

\section{LAMPIRAN}

Lampiran yang perlu disampaikan sebagai pendukung artikel, dituliskan setelah Biodata penulis. Maksimal sebanyak 4 (empat) halaman, diizinkan untuk bagian lampiran. Bila menyertakan tabel, gambar, atau persamaan matematika, juga diberi nomor berurutan.

\section{J.Jommit}


No.8. 